\title{
PENGARUH PENGGUNAAN GOOGLE CLASSROOM TERHADAP MOTIV ASI BELAJAR PESERTA DIDIK MATA PELAJARAN PAI DI SMK DARUL HIDAYAH MALANG
}

\author{
Ning Fina Inayatus Sofa \\ Universitas Islam Negeri Sunanpel Surabaya \\ e-mail: finainayatussofa@gmail.com
}

\begin{abstract}
Motivation is an important thing that needs to be considered. There are several factors that influence learning motivation, while one of them is the use of media in the learning process is a Google classroom. This research is a type of quantitative research with experimental research method, the subject in this research is the students of SMK Darul Hidayah class X. The object studied is the use of google classroom on the learning motivation of students in Islamic Education subjects. The data collection tool is the attitude scale, the rating scale model. Meanwhile, the data analysis technique used paired sample T-test. Based on the T-paired statistical test, the mean value of the difference between pretest (before being given treatment) and posttest (after being given treatment) was -13.733 with a standard deviation of 11.744. And obtained a significant value (2tailed) 0.000 , then Ha is accepted and $\mathrm{HO}$ is rejected, which means that there is a significant difference in the pretest and posttest.
\end{abstract}

\section{ABSTRAK}

Motivasi merupakan hal penting yang perlu diperhatikan. Terdapat beberapa faktor yang mempengaruhi motivasi belajar, adapun salah satunya yakni penggunaan media dalam proses pembelajaran yaitu Google classroom. Penelitian ini merupakan jenis penelitian kuantitatif dengan metode penelitian experiment,subjek dalam penelitian ini adalah peserta didik SMK Darul Hidayah kelas X. Objek yang diteliti adalah penggunaan google classroom terhadap motivasi belajar peserta didik mata pelajaran PAI. Alat pengumpulan data yaitu skala sikap model rating scale. Sedangkan teknik analsis data menggunakan uji paired sample T-test. Berdasarkan uji statistik T-paired diperoleh nilai rata-rata perbedaan antara pretest (sebelum diberikan treatment) dengan posttest (sesudah diberikan treatment) yaitu $-13,733$ dengan standar deviation 11,744. Dan didapatkan nilai Signifikan (2-tailed) 0,000 maka $\mathrm{H}^{\mathrm{a}}$ diterima dan $\mathrm{H}^{0}$ di tolak yang artinya ada perbedaan yang signifikan terhadap pretest dan postest.

\section{ARTICLE HISTORY}

Received 12 Agustus 2020

Revised 21 Agustus 2020

Accepted 25 Agustus 2020

\section{KEYWORDS}

Google Classroom, Motivasi

Belajar, Pendidikan Agama Islam 


\section{PENDAHULUAN}

Dalam kegiatan belajar mengajar, motivasi merupakan hal penting yang perlu diperhatikan, karena motivasi merupakan daya penggerak mencakup keseluruhan untuk mencapai suatu tujuan. Menurut Hamalik, motivasi adalah terjadinya reaksi dalam diri seseorang untuk mencapai suatu tujuan yang di inginkan. Di era sekarang, seiring berkembangnya teknologi memberikan peluang bagi guru untuk memupuk ketrampilan dalam memakai media ajar dan bahan ajar. Dengan tujuan dapat menumbuhkan motivasi peserta didik untuk lebih semangat dalam melaksanakan kegiatan belajar. Sebagaimana yang tercantum dalam Peraturan Menteri Pendidikan dan Kebudayaan No.65 tahun 2013, tentang pemanfaatan teknologi informasi untuk meningkatkan efisiensi dan efektifitas pembelajaran. penggunaan teknologi informasi menjadikan kegiatan pembelajaran disekolah menjadi lebih menarik, aktif dan kreatif. Tujuannya untuk mendorong penyelenggaraan pembelajaran yang efektif dan efisien. Dengan demikian, pembelajaran dengan integrasi teknologi informasi merupakan upaya untuk meningkatkan mutu dan kualitas kegiatan belajar mengajar.

Dalam rangka mensinergikan proses modernisasi dan kualitas pembelajaran, Pembelajaran di era modern, lebih diarahkan pada aktivitas modernisasi dengan bantuan teknologi canggih dengan harapan dapat membantu peserta didik dalam mencerna materi pelajaran secara interaktif, produktif, efektif, inspiratif, konstruktif, dan menyenangkan. Selain itu, peserta didik juga diharapkan memiliki life skill dari aplikasi teknologi tersebut. Adapun aplikasi dari teknologi informasi dan komunikasi yang potensial untuk dimanfaatkan sebagai media pembelajaran ialah internet, sudah cukup banyak sekolah-sekolah yang memiliki komputer yang terkoneksi (link) ke internet.

Google For Education merupakan inovasi yang menarik dari Google.Google For Education merupakan produk yang dibuat untuk memberikan kesempatan kepada para guru untuk mengeksplorasi gagasan keilmuan yang dimilikinya kepada peserta didik. Seperti yang dituliskan pada situs resminya,Google For 
Ning Fina Inayatus Sofa, Pengaruh Penggunaan Google Classroom terhadap Motivasi

Belajar Peserta Didik Mata Pelajaran PAI di SMK Darul Hidayah Malang

DOI: htts://doi.org/10.19105/rjpai.v1i2.4111

Education memiliki beberapa layanan yang sangat membantu dalam proses belajar mengajar di sekolah, seperti;Google Classroom, Google Mail, Google Calendar, Google Drive, dan Google Docs.

Mata pelajaran PAI merupakan mata pelajaran yang berisi tentang pengetahuan agama islam. Untuk memahaminya dibutuhkan suatu motivasi yang tinggi. Maka, agar peserta didik dapat mempunyai motivasi tinggi untuk belajar PAI perlu adanya dukungan media belajar. pemanfaatan teknologi informasi dalam pembelajaran seperti internet, laptop, dan handphone merupakan salah satu media yang dapat dipakai dalam pembelajaran PAI.

Dalam pemanfaatan suatu media belajar, seorang pendidik harus mampu memilih media yang sesuai dengan karakter peserta didik dan kebutuhan peserta didik, seperti dalam penggunaan aplikasi google classroom apakah sudah sesuai jika dipakai pada pembelajaran jenjang SMK, demikian juga apakah google classroom berpengaruh terhadap motivasi belajar peserta didik. Oleh karena itu peneliti memilih SMK Darul Hidayah sebagai objek penelitian untuk melihat pengaruh penggunaan google classroom terhadap motivasi belajar peserta didik mata pembelajaran PAI. penelitian ini bertujuan untuk mengetahui adakah pengaruh yang signifikan penggunaan google classroom terhadap motivasi belajar peserta didik mata pelajaran PAI di SMK Darul Hidayah Tirtoyudo Kabupaten Malang.

\section{METODE PENELITIAN}

Penelitian ini menggunakan pendekatan kuantitatif dengan metode penelitian eksperimen. Variabel penelitian yang digunakan dalam penelitian ini terdiri dari dua variabel: 1) Variabel terikat: motivasi belajar peserta didik dan 2) Variabel bebas : penggunaan google classroom. subyek dalam penelitian ini adalah peserta didik SMK Darul Hidayah kelas $X$ yang berjumlah 15 peserta didik. Sedangkan objek yang akan diteliti adalah penggunaan google classroom dalam pembelajaran PAI terhadap motivasi belajar peserta didik. Objek dalam penelitian ini di ambil melalui teknik purposive sampling, Bentuk desain 
eksperimen ini adalah penelitian eksperimen kuasi, dengan one- group pretestposttest design. Pelaksanaan eksperimen menggunakan satu kelompok dengan di ukur variabel terikatnya (pretest), kemudian diberi stimulus atau treatmentnya dan di ukur kembali variabel dependennya (posttes) tanpa adanya kelompok pembanding. Instrumen pengumpulan data yang digunakan dalam penelitian ini adalah skala sikap dengan jenis rating scale. Uji validitas skala, peneliti menggunakan validitas konstruk dengan uji pearson product moment. Dari 20 item yang telah di uji cobakan pada 35 reponden diperoleh 18 item yang valid dan 2 item tidak valid. Uji reliabilitas dilakukan dengan melihat kondisi internal berdasarkan alpha cronbach's. Hasil uji reliabilitas memperoleh 0,9 yang artinya reliabel.

Teknik analisis data dalam penelitian ini melalui dua tahap yakni, 1) Uji normalitas digunakan untuk mengetahui apakah sampel yang diperoleh berdistribusi normal atau tidak. penelitian ini uji normalitasnya menggunakan uji statistik dengan progam SPSS yaitu uji shapiro-wilk. 2) Uji hipotesis digunakan untuk mengetahui apakah terdapat pengaruh yang signifikan penggunaan google classroom terhadap motivasi belajar peserta didik mata pelajaran PAI di SMK Darul Hidayah Tirtoyudo kabupaten Malang. melalui uji paired sampel t-test.

\section{HASIL DAN PEMBAHASAN}

1. Uji normalitas

Uji normalitas digunakan untuk mengetahui apakah sampel yang diperoleh berdistribusi normal atau tidak. penelitian ini ditentukan uji normalitasnya menggunakan uji statistik dengan bantuan program SPSS yaitu dengan uji shapiro-wilk. Hasil uji normalitas penelitan ini dapat di lihat pada tabel berikut :

Tabel 1: Hasil uji normalitas

\begin{tabular}{|l|c|l|c|l|c|c|}
\hline \multicolumn{7}{|c|}{ Case Processing Summary } \\
\hline \multirow{4}{*}{} & \multicolumn{5}{|c|}{ Cases } \\
\cline { 2 - 7 } & \multicolumn{2}{|c|}{ Valid } & \multicolumn{2}{c|}{ Missing } & \multicolumn{2}{c|}{ Total } \\
\cline { 2 - 7 } & $\mathrm{N}$ & Percent & $\mathrm{N}$ & Percent & $\mathrm{N}$ & Percent \\
\hline
\end{tabular}


Ning Fina Inayatus Sofa, Pengaruh Penggunaan Google Classroom terhadap Motivasi

Belajar Peserta Didik Mata Pelajaran PAI di SMK Darul Hidayah Malang

DOI: htts://doi.org/10.19105/rjpai.v1i2.4111

\begin{tabular}{|l|r|r|r|r|r|r|}
\hline PRETEST & 15 & $100,0 \%$ & 0 & $0,0 \%$ & 15 & $100,0 \%$ \\
\hline POSTEST & 15 & $100,0 \%$ & 0 & $0,0 \%$ & 15 & $100,0 \%$ \\
\hline
\end{tabular}

\begin{tabular}{|c|c|c|c|c|}
\hline \multicolumn{5}{|c|}{ Descriptives } \\
\hline & & & Statistic & Std. Error \\
\hline \multirow[t]{13}{*}{ PRETEST } & \multicolumn{2}{|l|}{ Mean } & 55,4000 & 2,68470 \\
\hline & \multirow[t]{2}{*}{$\begin{array}{l}\text { 95\% Confidence } \\
\text { Interval for Mean }\end{array}$} & $\begin{array}{l}\text { Lower } \\
\text { Bound }\end{array}$ & 49,6419 & \\
\hline & & $\begin{array}{l}\text { Upper } \\
\text { Bound }\end{array}$ & 61,1581 & \\
\hline & \multicolumn{2}{|l|}{ 5\% Trimmed Mean } & 55,1667 & \\
\hline & \multicolumn{2}{|l|}{ Median } & 51,0000 & \\
\hline & \multicolumn{2}{|l|}{ Variance } & 108,114 & \\
\hline & \multicolumn{2}{|l|}{ Std. Deviation } & 10,39780 & \\
\hline & \multicolumn{2}{|l|}{ Minimum } & 40,00 & \\
\hline & \multicolumn{2}{|l|}{ Maximum } & 75,00 & \\
\hline & \multicolumn{2}{|l|}{ Range } & 35,00 & \\
\hline & \multicolumn{2}{|l|}{ Interquartile Range } & 15,00 & \\
\hline & \multicolumn{2}{|l|}{ Skewness } & ,595 & ,580 \\
\hline & \multicolumn{2}{|l|}{ Kurtosis } &,- 659 & 1,121 \\
\hline \multirow{13}{*}{ POSTEST } & \multicolumn{2}{|l|}{ Mean } & 69,1333 & 2,07907 \\
\hline & \multirow[t]{2}{*}{$\begin{array}{l}\text { 95\% Confidence } \\
\text { Interval for Mean }\end{array}$} & $\begin{array}{l}\text { Lower } \\
\text { Bound }\end{array}$ & 64,6742 & \\
\hline & & $\begin{array}{l}\text { Upper } \\
\text { Bound }\end{array}$ & 73,5925 & \\
\hline & \multicolumn{2}{|l|}{ 5\% Trimmed Mean } & 69,3148 & \\
\hline & \multicolumn{2}{|l|}{ Median } & 70,0000 & \\
\hline & \multicolumn{2}{|l|}{ Variance } & 64,838 & \\
\hline & \multicolumn{2}{|l|}{ Std. Deviation } & 8,05221 & \\
\hline & \multicolumn{2}{|l|}{ Minimum } & 55,00 & \\
\hline & \multicolumn{2}{|l|}{ Maximum } & 80,00 & \\
\hline & \multicolumn{2}{|l|}{ Range } & 25,00 & \\
\hline & \multicolumn{2}{|l|}{ Interquartile Range } & 12,00 & \\
\hline & \multicolumn{2}{|l|}{ Skewness } &,- 533 &, 580 \\
\hline & \multicolumn{2}{|l|}{ Kurtosis } &,- 609 & 1,121 \\
\hline
\end{tabular}

\section{Tests of Normality}




\begin{tabular}{|l|r|r|r|r|r|r|}
\hline & \multicolumn{3}{|c|}{ Kolmogorov-Smirnov $^{\mathrm{a}}$} & \multicolumn{3}{|c|}{ Shapiro-Wilk } \\
\cline { 2 - 7 } & Statistic & \multicolumn{1}{|c|}{$\mathrm{df}$} & \multicolumn{1}{|c|}{ Sig. } & Statistic & \multicolumn{1}{c|}{ df } & \multicolumn{1}{|c|}{ Sig. } \\
\hline PRETEST & 197 & 15 &, 120 &, 922 & 15 &, 205 \\
\hline POSTEST & 160 & 15 &, $200^{*}$ &, 932 & 15 &, 294 \\
\hline *. This is a lower bound of the true significance. \\
\hline \\
a. Lilliefors Significance Correction \\
\hline
\end{tabular}

Uji normalitas di atas digunakan untuk mengetahui apakah sebaran normal atau tidak normal. Kaidah yang digunakan adalah jika P (Asymp. Sig. P $>0,05$ maka sebaran dikatakan normal. Sebaliknya jika $\mathrm{P}<0,05$ maka sebaran dikatakan tidak normal. Dari hasil uji normalitas di atas item pretest memperoleh $\mathrm{P}=0,205$ ) dan item postest memperoleh $\mathrm{P}=0,295$ hal itu menunjukan bahwa uji normalitas berdistribusi normal $(P>0,05)$.

2. Uji hipotesis

Uji hipotesis digunakan untuk mengetahui apakah terdapat pengaruh yang signifikan penggunaan google classroom terhadap motivasi belajar peserta didik mata pelajaran PAI di SMK Darul Hidayah Tirtoyudo kabupaten Malang. Rumus yang digunakan adalah uji t ( $t$-paired.) dengan bantuan progam SPSS. Berikut ini hasil uji T-paired:

Tabel 2: Hasil uji hipotesis

\begin{tabular}{|l|l|r|r|r|r|}
\hline \multicolumn{7}{|c|}{ Paired Samples Statistics } \\
\hline \multirow{2}{*}{} & Mean & N & $\begin{array}{c}\text { Std. } \\
\text { Deviation }\end{array}$ & $\begin{array}{c}\text { Std. Error } \\
\text { Mean }\end{array}$ \\
\hline \multirow{2}{*}{ Pair 1 } & PRETEST & 55,40 & 15 & 10,398 & 2,685 \\
\cline { 2 - 7 } & POSTEST & 69,13 & 15 & 8,052 & 2,079 \\
\hline
\end{tabular}

Berdasarkan dari tabel (4.2) di atas, di peroleh nilai rata-rata pretest 55,40 dengan standart deviasi 10,398 dan standart eror 2,685. Sedangkan postest memperoleh nilai rata-rata 69,13 dengan standart deviasi 8,052 dan standart eror 2,079

Tabel 3: Paired sample corelation

\begin{tabular}{|c|c|c|c|}
\hline \multicolumn{5}{|c|}{ Paired Samples Correlations } \\
\hline & $\mathrm{N}$ & $\mathrm{n}$ & Sig. \\
\hline
\end{tabular}




\begin{tabular}{|l|l|r|r|r|}
\hline Pair 1 & PRETEST \& POSTEST & 15 &, 209 &, 454 \\
\hline
\end{tabular}

Tabel 4: Paired sample test

\begin{tabular}{|c|c|c|c|c|c|c|c|c|c|}
\hline \multicolumn{10}{|c|}{ Paired Samples Test } \\
\hline & & \multicolumn{5}{|c|}{ Paired Differences } & \multirow[b]{3}{*}{$\mathrm{t}$} & \multirow[b]{3}{*}{$\mathrm{df}$} & \multirow{3}{*}{$\begin{array}{l}\text { Sig. } \\
\text { (2- } \\
\text { taile } \\
\text { d) }\end{array}$} \\
\hline & & \multirow[b]{2}{*}{ Mean } & \multirow{2}{*}{$\begin{array}{l}\text { Std. } \\
\text { Deviati } \\
\text { on }\end{array}$} & \multirow{2}{*}{$\begin{array}{l}\text { Std. } \\
\text { Error } \\
\text { Mean }\end{array}$} & \multicolumn{2}{|c|}{$\begin{array}{c}95 \% \\
\text { Confidence } \\
\text { Interval of } \\
\text { the } \\
\text { Difference }\end{array}$} & & & \\
\hline & & & & & Lower & $\begin{array}{c}\text { Upp } \\
\text { er }\end{array}$ & & & \\
\hline Pair & PRETES & & 11,744 & 3,032 & & & - & 14 & 000 \\
\hline 1 & $\begin{array}{l}\mathrm{T}- \\
\text { POSTES } \\
\mathrm{T}\end{array}$ & 13,733 & & & 20,237 & 7,230 & 4,529 & & \\
\hline
\end{tabular}

Berdasarkan dari tabel (4.4) di atas diperoleh nilai rata-rata pretest(sebelum di berikan treatment) dengan nilai postest(sesudah diberikan treatment) yaitu -13,733 dengan standar deviation 11,744. Dan didapatkan nilai Signifikan (2tailed) 0,000 maka $\mathrm{H}^{a}$ diterima dan $\mathrm{H}^{0}$ di tolak. Jadi dapat disimpulkan ada perbedaan yang signifikan terhadap pretest dan postest.

Penelitian ini bertujuan untuk mengetahui pengaruh penggunaan gooogle classroom terhadap motivasi belajar peserta didik kelas $\mathrm{X}$ pada materiPAI di SMK Darul hidayah Tirtoyudo-kab. Malang. Data yang di peroleh dari hasil penelitian kemudian dilakukan analisis melalui uji statistik Paired Sample T-test. Berdasarkan hasil uji statistik tersebut diperoleh nilai signifikasi 0.000 kurang dari 0.05 maka Ha diterima dan Ho ditolak. Artinya terdapat perbedaan yang signifikan pada motivasi belajar peserta didik sebelum dan sesudah menggunakan google classroom.

Hasil analisis di atas menunjukan bahwa dengan menggunakan media belajar online (GoogleClassroom) dalam pembelajaran dapat meningkatkan motivasi belajar peserta didik. Hal ini sejalan dengan penelitian Suardiman 
$\mathrm{dkk}$, bahwa e-Learning berpengaruh positif terhadap motivasi belajar peserta didik, karena e-learning merupakan pembelajaran yang bervariasi, sangat menarik dan inovatif. ${ }^{1}$ Demikian juga hasil penelitian Agustin, E-learning dapat mengurangi kejenuhan peserta didik, sehingga peserta didik dapat termotivasi untuk belajar berfikir kritis dalam memecahkan masalah yang ada dalam materi pelajaran.

Adanya motivasi yang tinggi dalam proses belajar peserta didik sangat penting. Mengenai hal ini gurulah yang mempunyai peran penting dalam meningkatkan motivasi belajar peserta didik. Adanya motivasi yang timbul dalam diri seseorang juga di pengaruhi oleh beberapa faktor, yakni faktor internal dan faktor eksternal, dimana salah satunya yaitu media belajar sebagai faktor yang mempengaruhi motivasi peserta didik. ${ }^{2}$ Pemakaian media pembelajaran yang tepat dalam proses belajar mengajar juga dapat membangkitkan keinginan dan minat yang baru. ${ }^{3}$ Selain itu, Sudjana dan Rivai juga mengemukakan bahwa "salah satu manfaat media pengajaran dalam proses belajar adalah pengajaran akan lebih menarik perhatian peserta didik sehingga dapat menumbuhkan motivasi belajar". 4 Maka dari itu seorang pendidik harus dapat memilih media belajar yang sesuai dengan kebutuhan dan tentunya harus memperhatikan pemilihan media yang dapat memotivasi belajar peserta didik, sehingga proses pembelajaran agar efektif dan efisien.

Teknologi informasi merupakan bagian dari media yang di pakai untuk menyampaikan ilmu pengetahuan terhadap seseorang. ${ }^{5} \mathrm{Di}$ era sekarang ini teknologi menawarkan beberapa model penyampaian seperti berupa audio,

\footnotetext{
${ }^{1}$ Doni Septumarsa Ibrahim dan Siti Partini Suardiman, “The Effects Of The Use Of E_learning On the Learning Motivation Andachiement In Mathematics Of The Student Of SDN Tahunan Yogyakarta," Jurnal Prima Edukasia Vol 2 No 1 (2014): 11.

2 Syamsu Yusuf, "Program Bimbingan dan Konseling di Sekolah" (Bandung: Rizqi Perss, 2009), 23.

${ }^{3}$ Ajang Mulyadi, M. Arief Ramdhany, dan Defrina Sari Tilawati, "Pengaruh Penggunaan Media Pembelajaran Terhadap Motivasi Belajar Siswa Pada Mata Pelajaran Akuntansi," Jurnal Akuntansi Dan Keuangan. Vol 4 No 1 (2016): 7.

${ }^{4}$ Nana Sudjana dan Ahmad Rivai, dalam Media Pengajaran (Bandung: Sinar Baru Algensindo, 2013), 2.

${ }^{5}$ Munir, "Pembelajaran Jarak Jauh Berbasis Teknologi Informasi dan Komunikasi" (Bandung: Alfabeta, 2009), 34.
} 
Ning Fina Inayatus Sofa, Pengaruh Penggunaan Google Classroom terhadap Motivasi

Belajar Peserta Didik Mata Pelajaran PAI di SMK Darul Hidayah Malang

DOI: htts://doi.org/10.19105/rjpai.v1i2.4111

video, gambar, tulisan, dan lain-lain, yang kesemuanya di kemas dengan baik melalui layanan online yang pada dasarnya teknologi informasi berperan sebagai media yang memberikan pelayanan baik dalam dunia pendidikan. Dalam dunia pendidikan pengetahuan dan informasi sangat erat kaitannya, maka dari itu, terjadinya akses yang mudah menjadi sangat penting dalam dunia pendidikan. Seperti halnya sistem yang di tawarkan oleh teknologi ke dalam dunia pendidikan, yakni adanya pembelajaran dengan berbagai model audio, visual, maupun audio visual dapat memudahkan pengajar untuk menyajikan materi pelajaran yang lebih menarik dan menyenangkan. ${ }^{6} \mathrm{Hal}$ ini sejalan dengan hasil penelitian Zabir, pembelajaran dengan menggunakan teknologi menunjukkan motivasi belajar peserta didik berada pada kategori sangat tinggi ditinjau dari keinginan yang menarik dalam belajar, dan adanya lingkungan belajar yang kondusif.7 Teknologi digital juga mempunyai dampak positif terhadap motivasi belajar peserta didik, karena beroperasi secara otomatis, cepat, berkualitas, efektif, efisien, mudah mentransfer data dan informasi ke media lain.

Kelebihan google classroom sesuai dengan pendapat Shampa, dapat membantu pendidik dan juga peserta didik dalam menyimpan suatu materi kedalam cloude, seperti google drive, yang dapat di akses secara otomatis dalam google classroom. ${ }^{8}$ Juga dapat menghemat biaya, dan ruang, karena tdak memakai kertas. Begitu juga penggunaannya praktis, dapat digunakan dimanapun dan kapanpun berada dengan menggunakan handphone yang

\footnotetext{
6 Abdul Kadir dan Terra CH Triwahyuni, "Pengenalan Teknologi Informasi" (Yogyakarta: Andi, 2003), 24.

7 Azhari Zabir, "Pengaruh pemanfaatan Teknologi Pembelajaran terhadap Motivasi belajar Siswa SMPN 1 Lansirang Kabupaten Pinrang," Fakultas Ilmu Sosial Universitas Negeri Makasar, $2018,2$.

8 Aulya Alamanda Putra, "Penerapan Model Pembelajaran Jarak Jauh Berbasis Media Goggle Classroom Untuk Keterampilan Menulis" (Bandung, Universitas Pendidikan Indonesia, 2017).
} 
mereka miliki. Sehingga peserta didik dapat belajar dimanapun berada tanpa harus membawa buku, dan alat tulis. ${ }^{9}$

Sedangkan mengenai kekurangan google classroom seperti jika peserta didik tidak kritis dan terjadi kesalahan materi dan berdampak pada pengetahuannya, hal ini dapat diatasi dengan pemantauan guru dalam belajar, yakni dengan memberikan ulangan tentang mata pelajaran yang diberikan guna untuk menguji pemahaman setiap peserta didik pada isi mata pelajaran tersebut. Demikian jika peserta didik di minta untuk memahami mata pelajaran dari literatur lain seperti sumber yang berasal dari media online, seorang pendidik juga harus memberikan pengertian pemahaman terhadap peserta didik tentang memilih sumber belajar yang sesuai dan benar, agar tidak berpengaruh negatif terhadap pengetahuannya.

kekurangan google classroom seperti yang di sebutkan Putra yakni penggunaannya harus tersambung dengan jaringan internet. ${ }^{10}$ Mengenai hal ini menjadi kekurangan dalam penggunaan google classroom ketika digunakan pada lokasi sekolah yang sulit menemukan jaringan internet atau bahkan tidak ada jaringan internet. Oleh karena itu sekolah tersebut dapat menggunakan media belajar lainnya yang dapat digunakan dalam pembelajaran tanpa \embutuhkan internet. Tentunya hal terpenting dalam memilih suatu media pembelajaran seorang pendidik harus memperhatikan kesesuaian media belajar dengan materi dan karakteristik peserta didik agar terciptanya pembelajaran yang efektif dan efisien.

Dari pembahasan ini dapat disimpulkan bahwa penggunaan google classroom sebagaimedia belajar dapat berpengaruh baik terhadap motivasi belajar peserta didik. Dengan kata lain, adanya usaha yang tekun dan terutama didasari adanya motivasi, maka seseorang yang belajar itu akan dapat

\footnotetext{
${ }^{9}$ Lidia Susanti, "Hubungan Penggunaan Google Classroom Sebagai Pemnbelajaran Efektif Dan Paperless Terhadap Nilai Hasil Belajar Kognitif Pada Pelajaran Biologi Di SMA Charis Malang," Artikel Jurnal IT Edu Universitas Negeri Surabaya Vol 02 No 01 (2017).

${ }^{10}$ Putra, "Penerapan Model Pembelajaran Jarak Jauh Berbasis Media Goggle Classroom Untuk Keterampilan Menulis."
} 
Ning Fina Inayatus Sofa, Pengaruh Penggunaan Google Classroom terhadap Motivasi

Belajar Peserta Didik Mata Pelajaran PAI di SMK Darul Hidayah Malang

DOI: htts://doi.org/10.19105/rjpai.v1i2.4111

melahirkan prestasi yang baik. Intensitas motivasi seorang peserta didik akan sangat menentukan tingkat pencapaian prestasibelajarnya.Maka dari itu, sangat penting bagi pendidik untuk memperhatikan media belajar yang dapat memotivasi belajar peserta didik. Salah satunya yakni dengan memakai media online (google classroom)karena media online mempunyai beberapa fitur yang menarik dan dapat digunakan sebagai media belajar.

\section{KESIMPULAN}

Berdasarkan hasil analisis data melalui uji statistik penelitian ini telah menjawab hipotesis yakni: memperoleh nilai rata-rata perbedaan antara pretest(sebelum di berikan treatment) dengan nilai postest(sesudah diberikan treatment) yaitu -13,733 dengan standar deviation 11,744. Dan didapatkan nilai Signifikan (2-tailed) 0,000 maka $\mathrm{H}^{\mathrm{a}}$ diterima dan $\mathrm{H}^{0}$ di tolak yang artinya ada perbedaan yang signifikan terhadap pretest dan postest.Jadidisimpulkan terdapat pengaruh yang signifikan penggunaan google classroom terhadap motivasi belajar peserta didik mata pelajaran PAI di SMK Darul Hidayah Tirtoyudo Kabupaten Malang.

\section{DAFTAR PUSTAKA}

Ibrahim, Doni Septumarsa, dan Siti Partini Suardiman. “The Effects Of The Use Of E_learning On the Learning Motivation Andachiement In Mathematics Of The Student Of SDN Tahunan Yogyakarta." Jurnal Prima Edukasia Vol 2 No 1 (2014): 11.

Kadir, Abdul, dan Terra CH Triwahyuni. Pengenalan Teknologi Informasi. Yogyakarta: Andi, 2003.

Mulyadi, Ajang, M. Arief Ramdhany, dan Defrina Sari Tilawati. "Pengaruh Penggunaan Media Pembelajaran Terhadap Motivasi Belajar Siswa Pada Mata Pelajaran Akuntansi." Jurnal Akuntansi Dan Keuangan. Vol 4 No 1 (2016): 7.

Munir. Pembelajaran Jarak Jauh Berbasis Teknologi Informasi dan Komunikasi. Bandung: Alfabeta, 2009. 
Putra, Aulya Alamanda. “Penerapan Model Pembelajaran Jarak Jauh Berbasis Media Goggle Classroom Untuk Keterampilan Menulis." Universitas Pendidikan Indonesia, 2017.

Sudjana, Nana, dan Ahmad Rivai. Dalam Media Pengajaran. Bandung: Sinar Baru Algensindo, 2013.

Susanti, Lidia. "Hubungan Penggunaan Google Classroom Sebagai Pemnbelajaran Efektif Dan Paperless Terhadap Nilai Hasil Belajar Kognitif Pada Pelajaran Biologi Di SMA Charis Malang." Artikel Jurnal IT Edu Universitas Negeri Surabaya Vol 02 No 01 (2017).

Yusuf, Syamsu. Program Bimbingan dan Konseling di Sekolah. Bandung: Rizqi Perss, 2009.

Zabir, Azhari. "Pengaruh pemanfaatan Teknologi Pembelajaran terhadap Motivasi belajar Siswa SMPN 1 Lansirang Kabupaten Pinrang." Fakultas Ilmu Sosial Universitas Negeri Makasar, 2018, 2. 